\title{
Acoustic Emission-Based Methodology to Evaluate Delamination Crack Growth Under Quasi-static and Fatigue Loading Conditions
}

\author{
Milad Saeedifar ${ }^{1,2}$ - Mehdi Ahmadi Najafabadi ${ }^{1}$ - Kaivan Mohammadi ${ }^{3}$. \\ Mohamad Fotouhi $^{4}$ - Hossein Hosseini Toudeshky ${ }^{5}$. Reza Mohammadi ${ }^{1}$
}

Received: 12 November 2016 / Accepted: 26 October 2017 / Published online: 16 November 2017

(C) The Author(s) 2017. This article is an open access publication

\begin{abstract}
The aim of this study was to investigate the applicability of acoustic emission (AE) technique to evaluate delamination crack in glass/epoxy composite laminates under quasi-static and fatigue loading. To this aim, double cantilever beam specimens were subjected to mode I quasistatic and fatigue loading conditions and the generated $\mathrm{AE}$ signals were recorded during the tests. By analyzing the mechanical and $\mathrm{AE}$ results, an analytical correlation between the AE energy with the released strain energy and the crack growth was established. It was found that there is a 3rd degree polynomial correlation between the crack growth and the cumulative AE energy. Using this correlation the delamination crack growth was predicted under both the static and fatigue loading conditions. The predicted crack growth values was were in a good agreement with the visually recorded data during the tests. The results indicated that the proposed AE-based method has good applicability to evaluate the delamination crack growth under quasi-static and fatigue loading conditions, especially when the crack is embedded within the structure and could not be seen visually.
\end{abstract}

Milad Saeedifar

milad.saeedifar@aut.ac.ir; m.saeedifar@tudelft.nl

1 Non-destructive Testing Lab, Department of Mechanical Engineering, Amirkabir University of Technology, $424 \mathrm{Hafez}$ Ave, 15914 Tehran, Iran

2 Structural Integrity \& Composites Group, Faculty of Aerospace Engineering, Delft University of Technology, Delft, The Netherlands

3 Department of Mechanical Engineering, Sharif University of Technology, Tehran, Iran

4 Department of Design and Mathematics, University of the West of England, Bristol BS16 1QY, UK

5 Department of Aerospace Engineering, Amirkabir University of Technology, Tehran, Iran
Keywords Quasi-static · Fatigue · Delamination · Acoustic emission $\cdot$ Fatigue crack growth

\section{Introduction}

Fiber reinforced plastic composites (FRP) have many advantages such as high specific strength, specific stiffness, etc. [1-4]. However, these materials suffer from different damage mechanisms, such as matrix cracking, fiber breakage and delamination [5-8]. The principal mode of failure in laminated composites is the separation along the interfaces of the layers, viz, delamination [9-14]. This failure results in dramatic reduction of residual strength and stiffness of the structure. Delamination occurs under different loading conditions, i.e. mode I, mode II and mode III. However, mode I delamination is the most common mode of failure occurred in the structures. This is due to lower energy that is required for the initiation of mode I delamination [1517].

Due to complexity of laminated composites, prediction of fatigue behavior in these materials is not straight forward [18]. Accurate measurement of fatigue crack growth has become a challenging issue in fracture mechanics analyses. Fatigue crack growth monitoring is a difficult and timeconsuming test [19]. In addition, work gets harder when the crack is embedded within the structure and could not be seen visually.

Acoustic emission (AE) is a naturally occurring phenomenon, which is the result of transient elastic wave propagation caused by a sudden release of energy inside the material [20]. There are various sources of AE events in composite materials such as matrix cracking, fiber/matrix debonding, fiber breakage, etc. [21-23]. Recently, AE has been utilized as an applicable technique to detect in-situ 
information from the damages that occur in laminated composites [5,24-27].

Some studies have used AE technique to investigate the delamination behavior under quasi-static loading condition [28-32]. Fotouhi and Ahmadi [33] investigate initiation of delamination in laminated composites under mixed-mode loading condition using AE technique. Arumugam et al. [34] investigated damage mechanisms in glass/epoxy composite specimens under mode I delamination using $\mathrm{AE}$ and fast Fourier transform (FFT) analysis. Saeedifar et al. [35] determined interlaminar fracture toughness of glass/ epoxy composites under mode I, II and mixed-mode I\&II loading using $\mathrm{AE}$ and finite element (FE) methods. The literature review shows that most $\mathrm{AE}$ based studies were focused on delamination initiation and there is a lack in the investigation of delamination propagation behavior using $\mathrm{AE}$ technique.

Due to the complexity of the fatigue phenomenon in composite materials, little work has been done on the behavior of delamination in laminated composites under cyclic loading using AE technique. Silversides et al. [36] studied delamination initiation in carbon/epoxy specimens under mixed-mode cyclic loading conditions. Romhany et al. [37] offered an algorithm to predict delamination crack in carbon/epoxy specimens subjected to cyclic loading. Romhany's method has two disadvantages: (a) to predict the fatigue crack growth at least two AE sensors must be utilized, and (b) the accurate AE wave propagation speeds in the specimens must first be calculated.

The aim of this paper is to investigate the delamination propagation in glass/epoxy composites under mode I quasistatic and fatigue loading conditions. The article is composed of two sections. In the first section, the delamination behavior under quasi-static loading condition is investigated using the mechanical and AE data. Then, the correlations between AE energy, the released strain energy and the crack growth are established theoretically and it is found that there is a 3rd degree polynomial correlation between the crack growth and the cumulative AE energy. Then, quasi-static delamination growth was predicted using the obtained correlation and the obtained AE signals. In the second section, the delamination crack growth under fatigue loading is predicted using the same concept as the static loading. The advantage of the proposed method is prediction of delamination crack growth using only one AE sensor without any need to determine AE wave propagation speed in the specimens. Consistency of the AE-based evaluated results and visually recorded values illustrates that the proposed $\mathrm{AE}$ method is more suitable than the conventional methods for detection of delamination crack growth in the laminated composites under quasi-static and fatigue loading conditions.
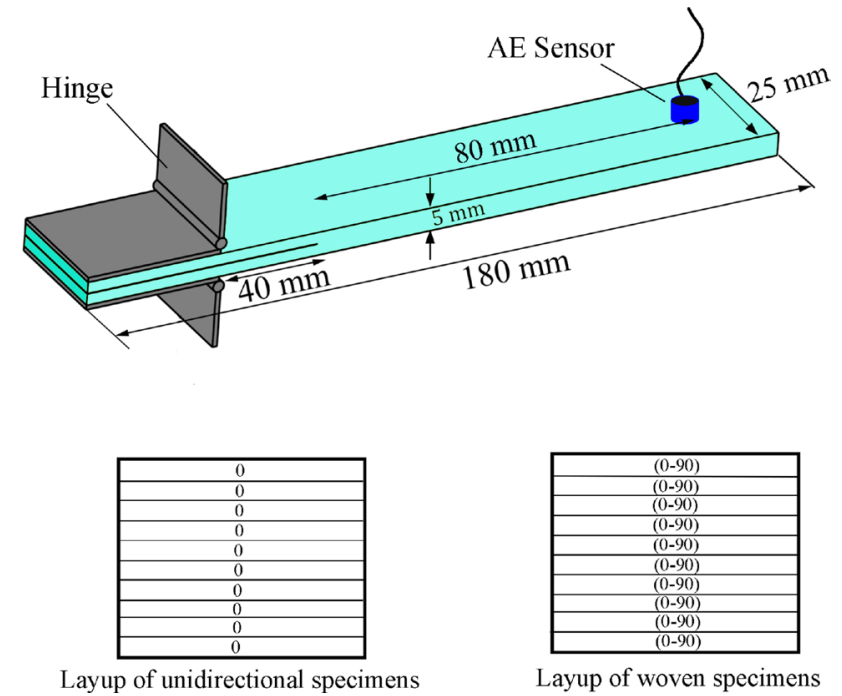

Fig. 1 The specimens geometry and dimensions

\section{Experimental Procedures}

\subsection{Materials and Specimens' Preparation}

The experimental work was carried out on laminates fabricated from an epoxy resin reinforced with unidirectional and woven E-glass fibers with the density of $1.17 \mathrm{~g} / \mathrm{cm}^{3}, 390$ and $300 \mathrm{~g} / \mathrm{m}^{2}$, respectively. The laminates were prepared by hand lay-up method. The starter crack was formed by inserting a Teflon film with a thickness of $20 \mu \mathrm{m}$ at the mid-plane during molding as an initial crack for the delamination. The laminated composite specimens consist of ten plies with a rectangular shape and uniform thickness. Characteristics of the specimens used for this study are illustrated in Fig. 1. For ease of use, the unidirectional specimen is called $U$ and the woven specimen is called $\mathrm{W}$.

\subsection{Test Procedure}

\subsubsection{Quasi-Static and Cyclic Loadings}

The specimens were subjected to quasi-static loading according to ASTM D5528 standard [38]. A properly calibrated tensile test machine (HIWA), in the range of $0.5-500 \mathrm{~mm} / \mathrm{min}$, and the displacement control mode were used for the tests. The tests were carried out at room temperature and at a constant displacement rate of $3 \mathrm{~mm} / \mathrm{min}$. The load and displacement were continuously recorded by the tensile machine and the crack length was recorded using a digital video camera (SONY HDR-XR150) with 25X optical zoom and $300 \mathrm{X}$ digital zoom.

The fatigue loading tests were performed by a properly calibrated tensile test machine (Dartec) according to ASTM 

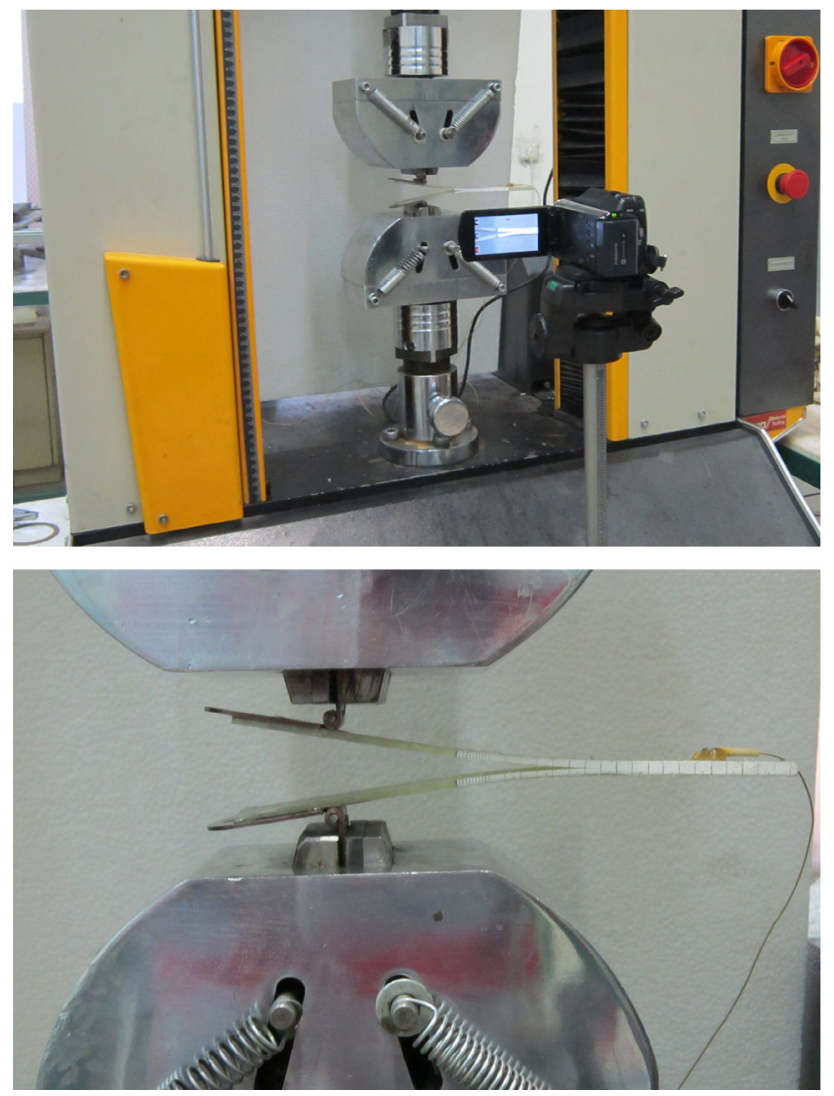

Fig. 2 The experimental test setup

D6115 [39]. Based on ASTM D6115 recommendation the tests were performed under displacement control mode with the loading frequency of $3 \mathrm{~Hz}$. For ease of working, the quasistatic and fatigue tested specimens are illustrated by ' $S$ ' and ' $F$ ' subscripts, respectively. The test apparatus is shown in Fig. 2.

\subsubsection{AE Device}

$\mathrm{AE}$ events were recorded using $\mathrm{AE}$ software AEWin and a data acquisition system Physical Acoustics Corporation (PAC) PCI-2 with a maximum sampling rate of $40 \mathrm{MHz}$. PICO which is a broadband, resonant-type, single-crystal piezoelectric transducer from PAC, was used as the AE sensor. The sensor has the resonance frequency of $513.28 \mathrm{kHz}$ and an optimum operating range of $100-750 \mathrm{kHz}$. In order to provide good acoustic coupling between the specimen and the sensor, the surface of the sensor was covered with grease. The signal was detected by the sensor and enhanced by a 2/4/6-AST preamplifier. The gain selector of the preamplifier was set to $37 \mathrm{~dB}$. The test sampling rate was $1 \mathrm{MHz}$ with 16 bits of resolution between 10 and $100 \mathrm{~dB}$. The AE sensor was placed on the surface of the sample with $80 \mathrm{~mm}$ distance from the delamination tip.
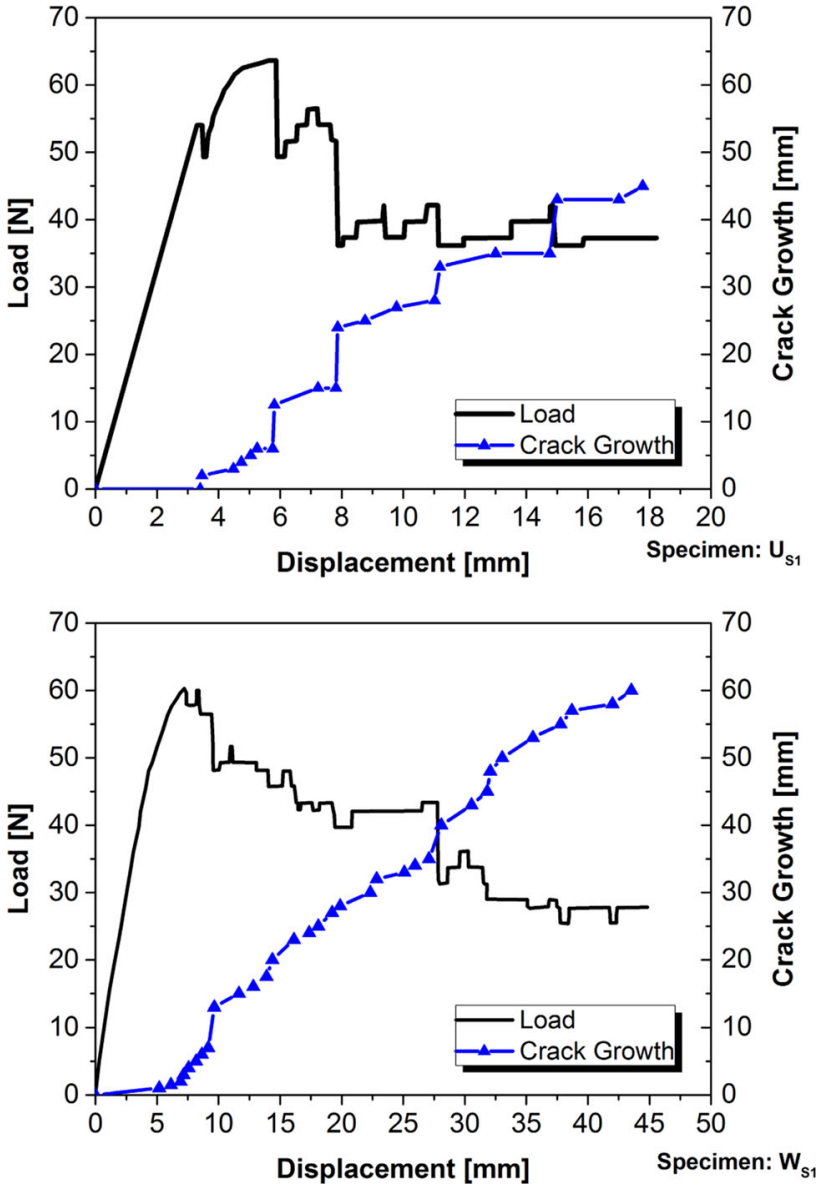

Fig. 3 Load-displacement and crack growth-displacement diagrams for the $\mathrm{U}_{\mathrm{S} 1}$ and $\mathrm{W}_{\mathrm{S} 1}$ specimens

\section{Results and Discussion}

\subsection{Quasi-Static Loading}

\subsubsection{Mechanical Results}

Figure 3 shows the load-displacement and crack growthdisplacement diagrams for the $\mathrm{U}_{\mathrm{S} 1}$ and $\mathrm{W}_{\mathrm{S} 1}$ specimens. As can be seen, the crack growth in the $\mathrm{W}_{\mathrm{S} 1}$ specimen is more stable than the $\mathrm{U}_{\mathrm{S} 1}$ specimen. These instabilities i.e. rise and fall behaviors, in the crack growth and load-displacement diagrams are called pop-in phenomenon [40]. The big pop-ins in the $\mathrm{U}_{\mathrm{S} 1}$ specimen occur due to fiber bridging phenomenon $[38,41,42]$. Fiber bridging phenomenon described as the stretching of some fibers between upper and lower layers of the crack plane. This phenomenon occurs near the crack tip and results in additional resistance against the crack growth $[41,42]$. When the stress in the bridged fibers reaches to the fibers strength, the fibers are broken and the crack propagates abruptly for a few millimeters. By bridging the new fibers, the crack is arrested again. Some small pop-ins in the $\mathrm{W}_{\mathrm{S} 1}$ specimen are due to the change in delamination propagation plane that is a common phenomenon in non-unidirectional 

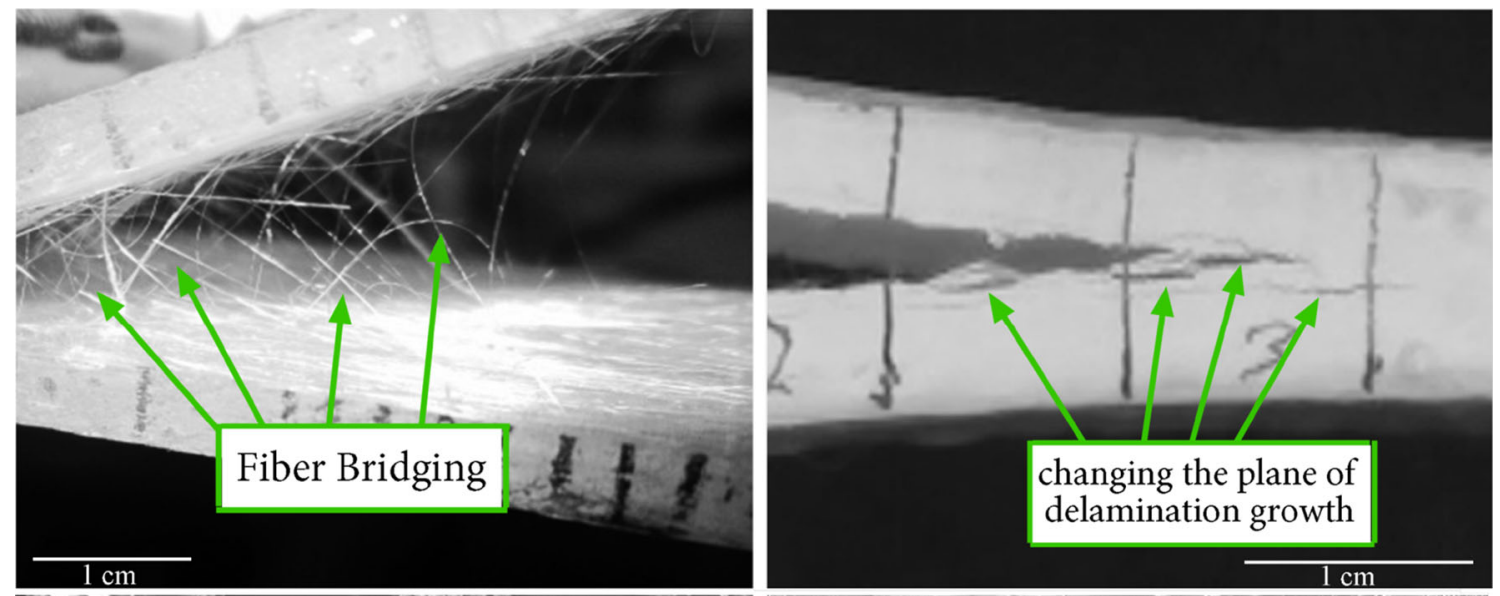

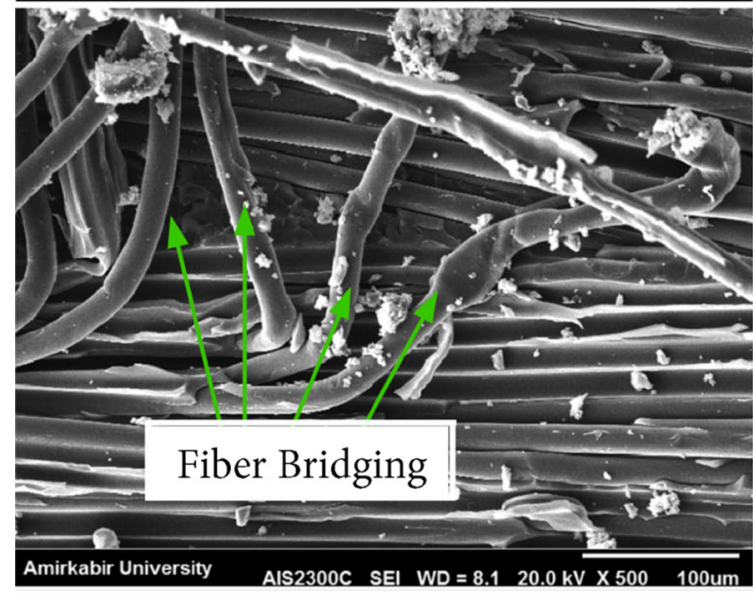

(a)

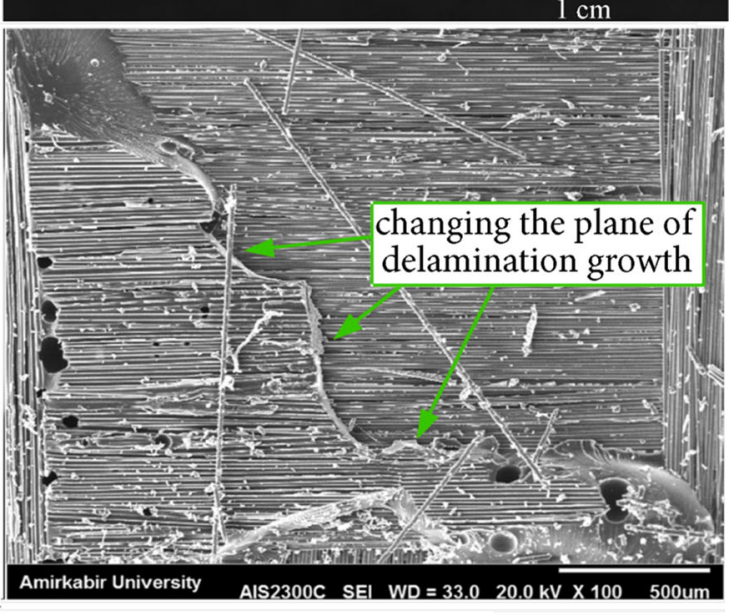

(b)

Fig. 4 Fiber bridging and crack plane changing in the investigated specimens $\mathbf{a} \mathrm{U}_{\mathrm{S} 1}$, and $\mathbf{b} \mathrm{W}_{\mathrm{S} 1}$

Fig. 5 Fiber bundle and pure resin tensile tests
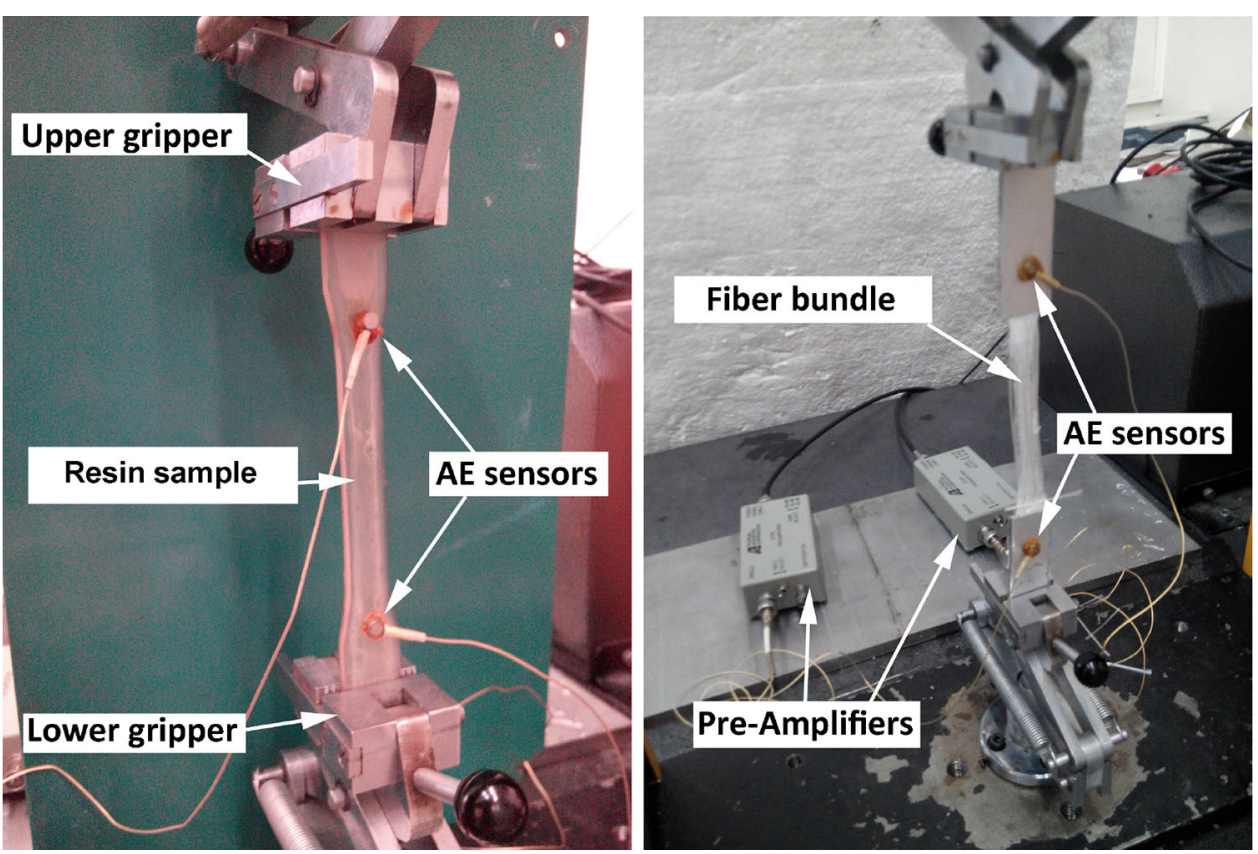

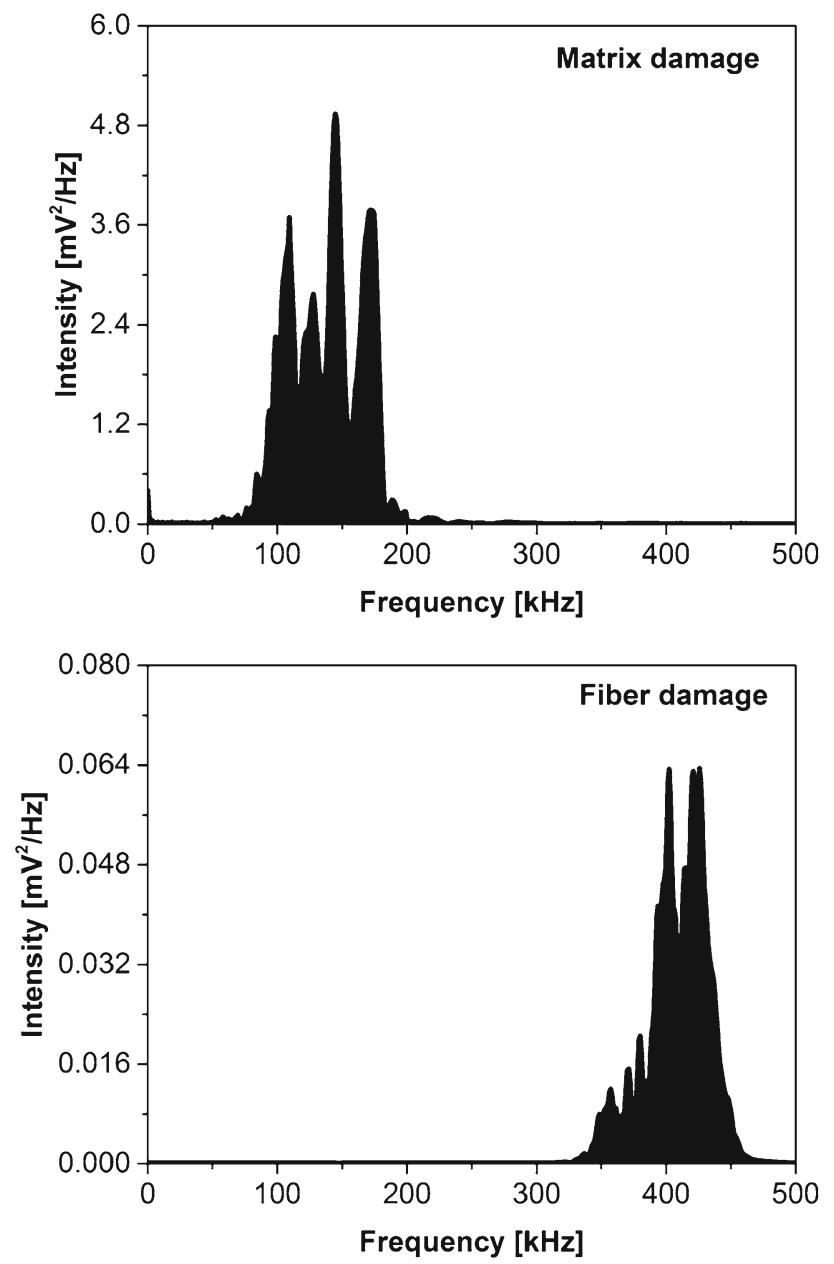

Fig. 6 Frequency distribution of matrix and fiber damages

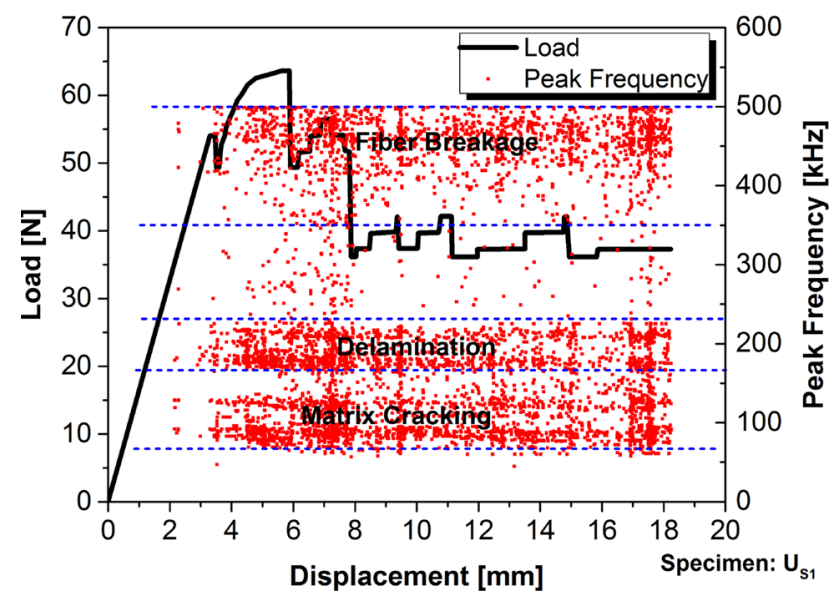

Fig. 7 Load- displacement and Frequency distribution of AE signals of the $\mathrm{U}_{\mathrm{S} 1}$ specimen

laminated composites (see Fig. 4). The top images of Fig. 4 show the macroscopic lateral view of the specimens. In the case of the $\mathrm{U}_{\mathrm{S} 1}$ specimen, bridged fibers between upper and lower surfaces of the crack are obvious, while in the case of the $\mathrm{W}_{\mathrm{S} 1}$ specimen, no bridged fiber is seen. However, in

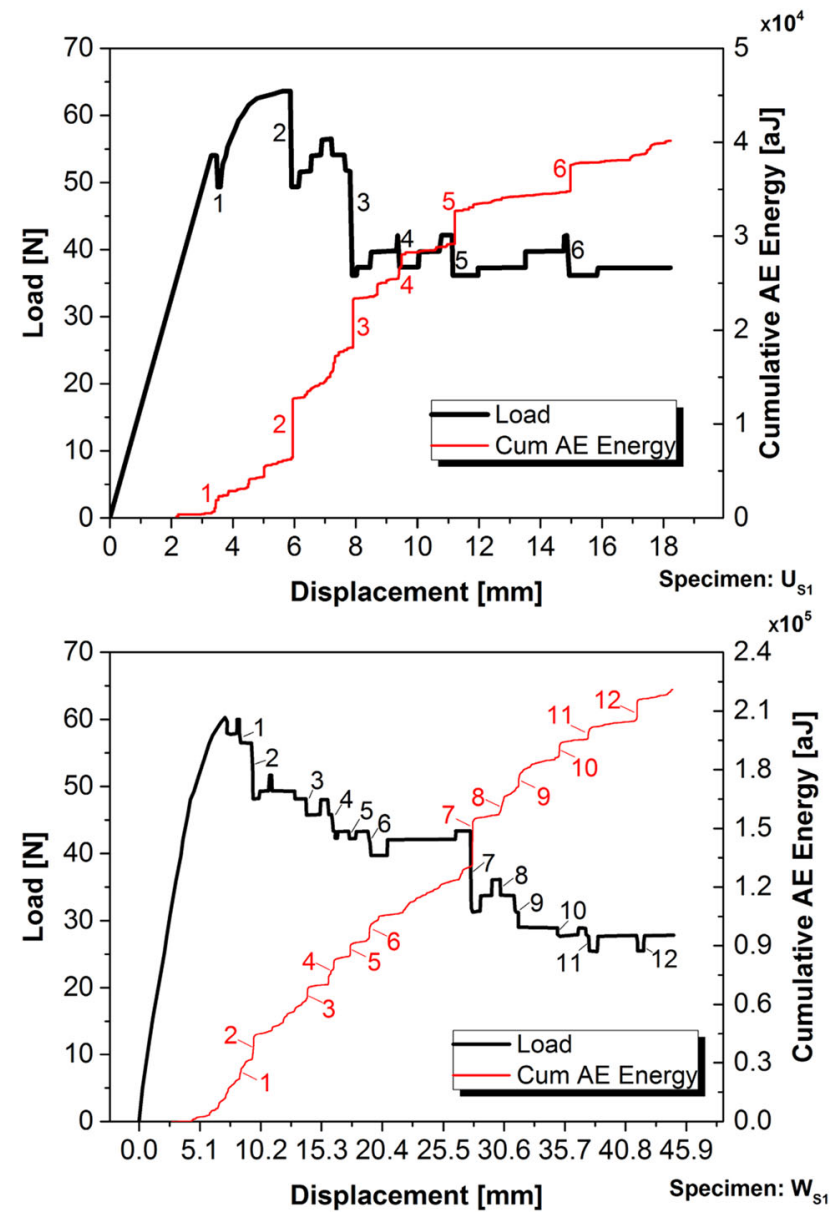

Fig. 8 Load-displacement and cumulative AE energy of delamination curves for the $\mathrm{U}_{\mathrm{S} 1}$ and $\mathrm{W}_{\mathrm{S} 1}$ specimens

the lateral view of the $\mathrm{W}_{\mathrm{S} 1}$ specimen, changing of the crack growth plane is observed. This is due to this fact that when the crack propagates and arrives to a warp of the woven fabric, it may not be able to continue its growth at the previous plane and it jumps from the warp and propagates at the adjacent layers. The bottom images of Fig. 4 show the microscopic view of the damaged surface of the specimens. In consistent with the macroscopic images, fiber bridging is observed in the $\mathrm{U}_{\mathrm{S} 1}$ specimen surface, while complete breaking of a layer and changing the crack growth plane are seen for the $\mathrm{W}_{\mathrm{S} 1}$ specimen.

\subsubsection{AE Results}

The most common damage mechanisms in laminated composites are matrix cracking, fiber breakage, and delamination [43-45]. In order to estimate delamination growth using $\mathrm{AE}$ technique, first, the $\mathrm{AE}$ signals originated from delamination damage must be specified and discriminated from the AE signals originated from other damage mechanisms. To this aim, tensile tests on pure resin and fiber bundle were conducted. 


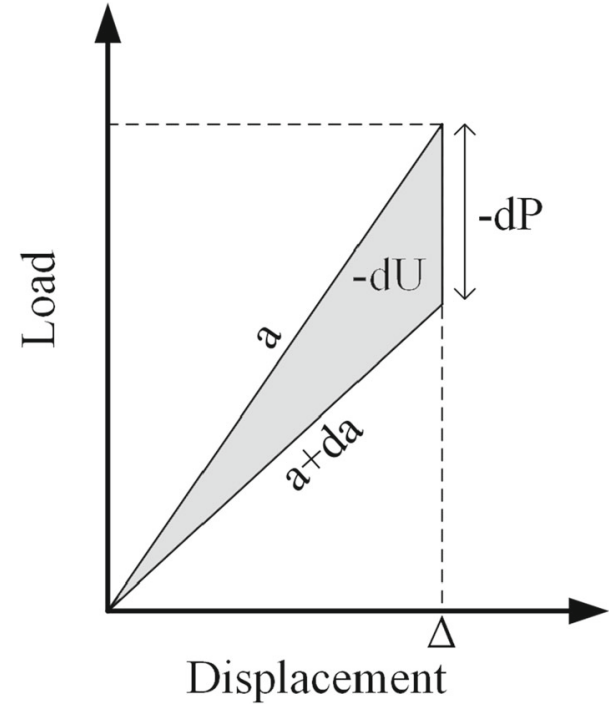

Fig. 9 Changing the strain energy due to infinitesimal crack growth under displacement control mode (a and da are crack length and infinitesimal crack growth, respectively)

The pure resin tensile test was performed on a tensile test sample made of epoxy resin and the fiber bundle test was conducted by a tension test on a bundle of about 1000 glass filaments. The AE signals were recorded by the AE sensors that were mounted on the surface of the resin and the fiber bundle (see Fig. 5). The AE signals obtained from the fiber bundle and pure resin tests were analyzed using Fast Fourier Transform (FFT) and the frequency range of the matrix damage and fiber breakage were obtained (see Fig. 6). As can be seen, frequency range of the matrix and fiber damages are $(70-170 \mathrm{kHz})$ and $(350-500 \mathrm{kHz})$, respectively.

The AE signals captured during the DCB tests can be classified according to the obtained frequency ranges for the pure resin and fiber bundle. Fig. 7 shows the load-displacement and the frequency distribution of the recoded AE signals for the $\mathrm{U}_{S 1}$ specimen. According to the frequency content of the AE signals, three distinct classes are observed. In consistency with the obtained frequency ranges of pure resin and fiber bundle tests (Fig. 6), class 1 signals are allocated to matrix cracking and class 3 signals are dedicated to fiber breakage. The only remained class with frequency range of [170-230 kHz] (i.e. class 2 ) is devoted to the only remained damage mechanisms, i.e. delamination. The frequency range of delamination is in consistent with the results of the previous research [46].

The following results, i.e. figures, tables, etc., are only related to the $\mathrm{AE}$ signals originated from delamination damage that are discriminated from the other damage mechanisms. Figure 8 shows load and cumulative AE energy of delamination versus displacement curves for the $\mathrm{U}_{\mathrm{S} 1}$ and $\mathrm{W}_{\mathrm{S} 1}$ specimens. In consistency with the crack growth curve in Fig. 3, each pop-in in the load curve is related to a sudden crack growth which is accompanied by a well-defined acoustic energy jump. By applying the load to the specimen, as long as the crack is arrested, the strain energy is stored in the specimen. When the stored strain energy reaches to its critical value, the crack propagates and the stored strain energy is released (see Fig. 9). According to Fig. 9, released strain energy at each pop-in $\left(\left.\mathrm{dU}\right|_{\Delta}\right)$, can be calculated by Eq. (1) [47]:

$$
\left.\mathrm{dU}\right|_{\Delta}=\frac{1}{2} \Delta \cdot \mathrm{dP}
$$

$\Delta$ and $\mathrm{dP}$ are displacement and load drop, respectively.

A part of this released energy transmits within the specimen in the form of stress waves [40,48], and we record these waves as AE signals. Thus, the energy of the recorded AE signals $\left(\triangle E_{A E}\right)$ is some proportion of the available elastic energy $(\Delta U)[48]$.

$$
\Delta U \sim \Delta E_{A E}
$$

Using Eq. (1), released strain energy at each pop-in was calculated. The corresponding AE energy jump at each popin was also calculated using the $\mathrm{AE}$ data recorded by the $\mathrm{AE}$ sensors. The obtained values of released strain energy (dU) and corresponded $\mathrm{AE}$ energy jump $\left(\mathrm{dE}_{\mathrm{AE}}\right)$ at each pop-in are represented in Tables 1 and 2.

Figure 10 illustrates the correlation between the $\mathrm{AE}$ energy jump and the released strain energy at the pop-ins. In consistent with Eq. (2), there is a linear relationship between

\begin{tabular}{|c|c|c|c|c|c|c|c|c|}
\hline Pop-in number & $\Delta(\mathrm{mm})$ & $\mathrm{P}_{1}(\mathrm{~N})$ & $\mathrm{P}_{2}(\mathrm{~N})$ & $\mathrm{dP}(\mathrm{N})$ & $\mathrm{E}_{\mathrm{AE}-1}\left(\times 10^{-18} \mathrm{~J}\right)$ & $\mathrm{E}_{\mathrm{AE}-2}\left(\times 10^{-18} \mathrm{~J}\right)$ & $\mathrm{dE}_{\mathrm{AE}}\left(\times 10^{-18} \mathrm{~J}\right)$ & $\mathrm{dU}\left(\times 10^{-3} \mathrm{~J}\right)$ \\
\hline 1 & 3.46 & 54.03 & 49.32 & 4.71 & 654 & 1882 & 1228 & 8.1483 \\
\hline 2 & 5.87 & 63.67 & 49.33 & 14.34 & 6641 & 12,560 & 5919 & 42.0879 \\
\hline 3 & 7.81 & 51.60 & 36.13 & 15.47 & 18,142 & 23393 & 5251 & 60.41035 \\
\hline 4 & 9.37 & 42.37 & 37.37 & 5.00 & 25,506 & 28,085 & 2579 & 23.425 \\
\hline 5 & 11.10 & 42.12 & 36.14 & 5.98 & 29,197 & 32,682 & 3485 & 33.189 \\
\hline 6 & 14.80 & 40.13 & 36.15 & 3.98 & 34,792 & 37,600 & 2800 & 29.452 \\
\hline
\end{tabular}

Table 1 The values of released strain energy $(\mathrm{dU})$ and $\mathrm{AE}$ energy jump $\left(\mathrm{dE}_{\mathrm{AE}}\right)$ at each pop-in for the $\mathrm{U}_{\mathrm{S} 1}$ specimen

$\mathrm{P}_{1}$ : the initial load at each pop-in, $\mathrm{P}_{2}$ : the final load at each pop-in, $\mathrm{dP}=\mathrm{P}_{1}-\mathrm{P}_{2}, \mathrm{E}_{\mathrm{AE}-1}$ : the initial cumulative AE energy at each pop-in, $\mathrm{E}_{\mathrm{AE}-2}$ : the final cumulative $\mathrm{AE}$ energy at each pop-in, $\mathrm{dE}_{\mathrm{AE}}=\mathrm{E}_{\mathrm{AE}-2}-\mathrm{E}_{\mathrm{AE}-1}$ 
Table 2 The values of released strain energy $(\mathrm{dU})$ and AE energy jump $\left(\mathrm{dE}_{\mathrm{AE}}\right)$ at each pop-in for the $\mathrm{W}_{\mathrm{S} 1}$ specimen

\begin{tabular}{|c|c|c|c|c|c|c|c|c|}
\hline Pop-in number & $\Delta(\mathrm{mm})$ & $P_{1}(N)$ & $\mathrm{P}_{2}(\mathrm{~N})$ & $\mathrm{dP}(\mathrm{N})$ & $\mathrm{E}_{\mathrm{AE}-1}\left(\times 10^{-18} \mathrm{~J}\right)$ & $\mathrm{E}_{\mathrm{AE}-2}\left(\times 10^{-18} \mathrm{~J}\right)$ & $\mathrm{dE}_{\mathrm{AE}}\left(\times 10^{-18} \mathrm{~J}\right)$ & $\mathrm{dU}\left(\times 10^{-3} \mathrm{~J}\right)$ \\
\hline 1 & 8.40 & 60.02 & 56.52 & 3.50 & 21,532 & 27,407 & 5875 & 14.70 \\
\hline 2 & 9.42 & 56.47 & 48.14 & 8.33 & 31,754 & 44,200 & 12,446 & 39.23 \\
\hline 3 & 13.10 & 48.14 & 45.76 & 2.38 & 61,722 & 68,800 & 7078 & 15.59 \\
\hline 4 & 15.90 & 48.04 & 42.31 & 5.73 & 70,417 & 83,029 & 12,612 & 45.56 \\
\hline 5 & 17.60 & 43.31 & 42.21 & 1.10 & 84,543 & 90,980 & 6437 & 9.68 \\
\hline 6 & 19.20 & 43.32 & 39.71 & 3.61 & 92,583 & 102,083 & 9500 & 34.66 \\
\hline 7 & 27.80 & 43.37 & 31.87 & 11.5 & 13,0481 & 154,709 & 24,228 & 159.85 \\
\hline 8 & 30.30 & 36.16 & 33.83 & 2.33 & 15,7063 & 166,107 & 9044 & 35.30 \\
\hline 9 & 31.40 & 33.72 & 29.00 & 4.72 & 16,7000 & 179,000 & 12,000 & 74.10 \\
\hline 10 & 35.10 & 28.95 & 27.68 & 1.27 & 18,6154 & 193,365 & 7211 & 22.28 \\
\hline 11 & 37.40 & 27.60 & 25.50 & 2.10 & 19,5470 & 201,836 & 6366 & 39.27 \\
\hline 12 & 41.70 & 27.78 & 25.50 & 2.28 & 20,4826 & 215,677 & 10,851 & 47.54 \\
\hline
\end{tabular}

$\mathrm{P}_{1}$ : the initial load at each pop-in, $\mathrm{P}_{2}$ : the final load at each pop-in, $\mathrm{dP}=\mathrm{P}_{1}-\mathrm{P}_{2}, \mathrm{E}_{\mathrm{AE}-1}$ : the initial cumulative $\mathrm{AE}$ energy at each pop-in, $\mathrm{E}_{\mathrm{AE}-2}$ : the final cumulative $\mathrm{AE}$ energy at each pop-in, $\mathrm{dE}_{\mathrm{AE}}=\mathrm{E}_{\mathrm{AE}-2}-\mathrm{E}_{\mathrm{AE}-1}$
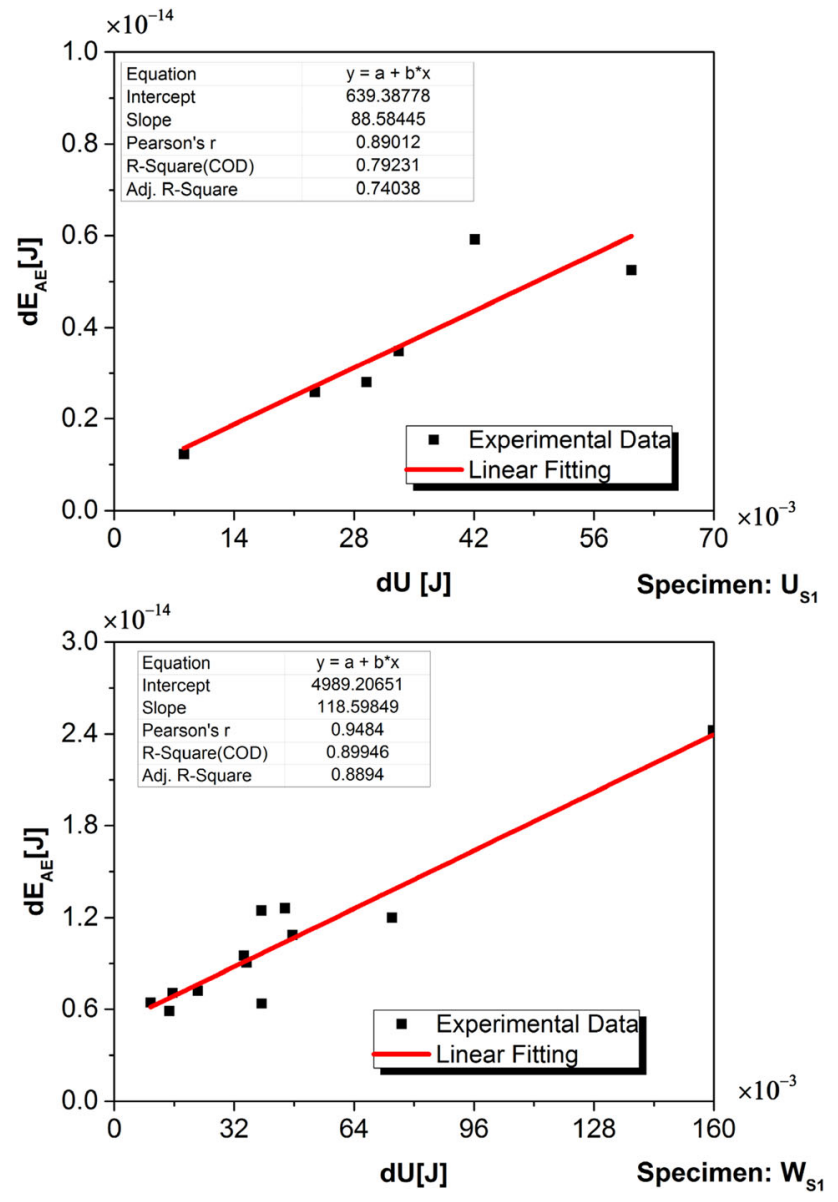

Fig. 10 Correlation between the AE energy jump and the strain energy drop at the pop-ins for the $\mathrm{U}_{\mathrm{S} 1}$ and $\mathrm{W}_{\mathrm{S} 1}$ specimens
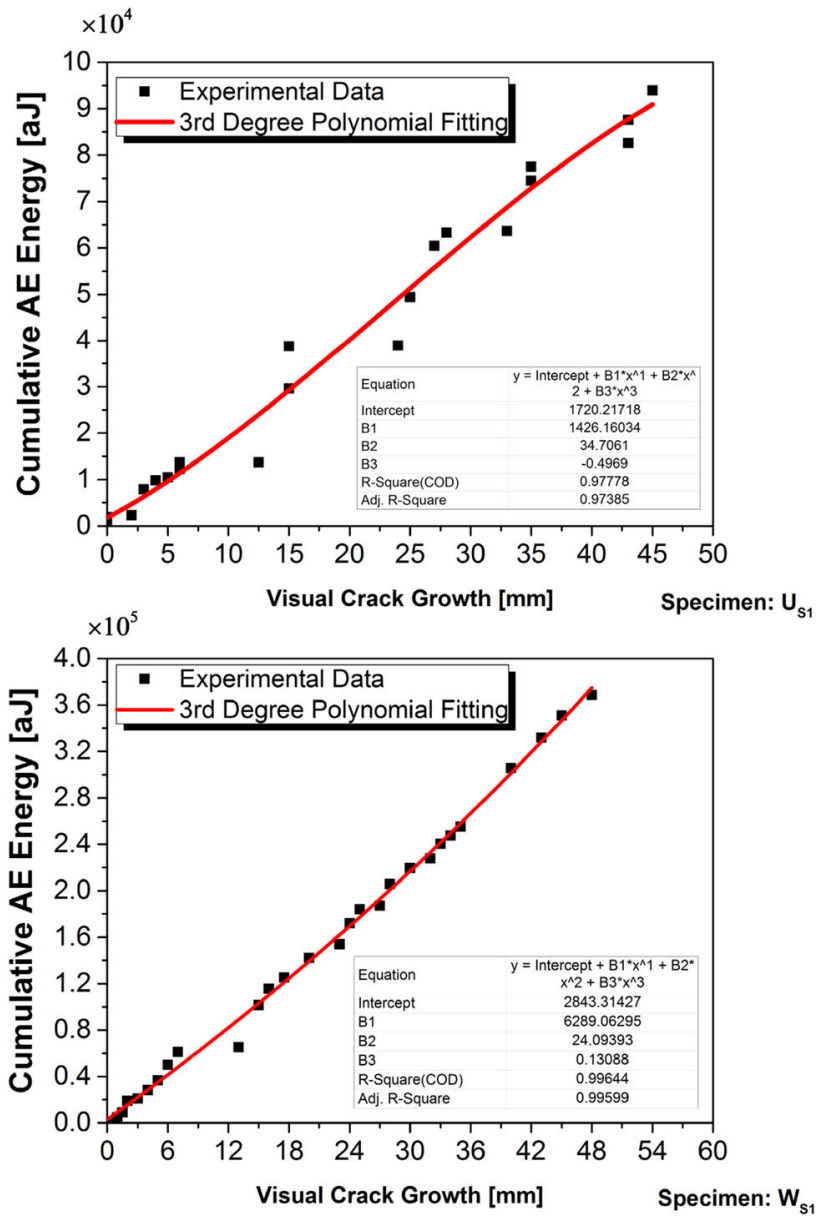

Fig. 11 Correlation between visual crack growth and cumulative AE energy of delamination for the $\mathrm{U}_{\mathrm{S} 1}$ and $\mathrm{W}_{\mathrm{S} 1}$ specimens 

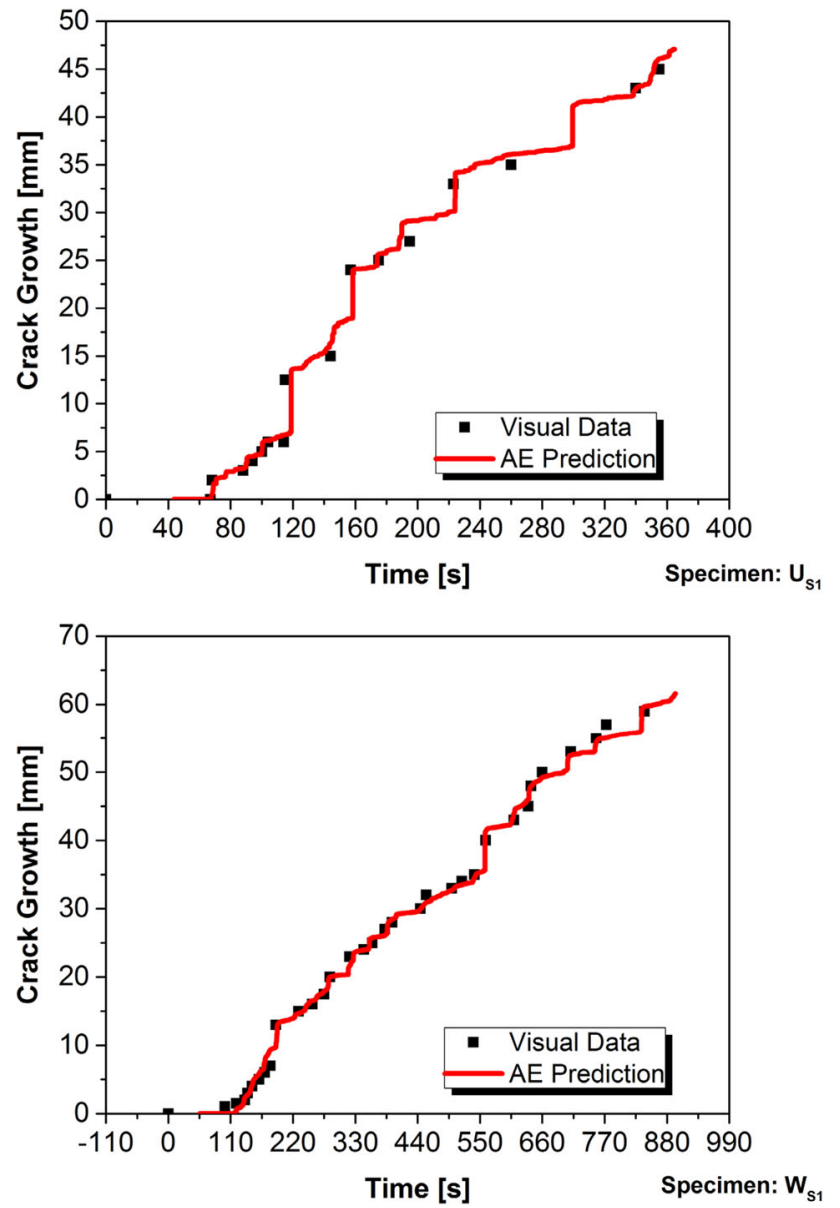

Fig. 12 Prediction of crack growth using the AE method for the $U_{S 1}$ and $\mathrm{W}_{\mathrm{S} 1}$ specimens

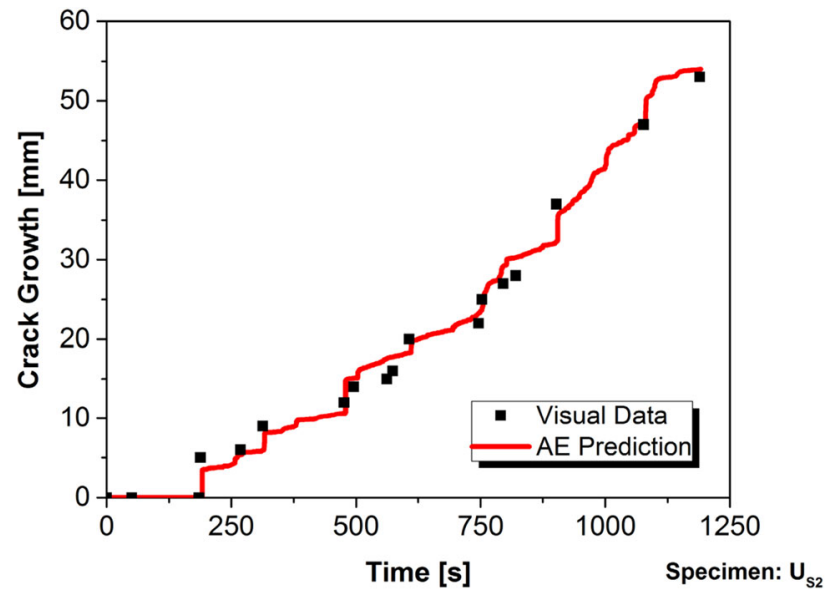

Fig. 13 Prediction of crack growth using the AE method for the $U_{\mathrm{S} 2}$ specimen

the AE energy jump and the released strain energy. Thus, amount of the AE energy, induced by the crack growth, is a function of the released strain energy.
Table 3 The maximum and average error of the AE crack growth prediction

\begin{tabular}{llll}
\hline Specimens & $\begin{array}{l}\text { Loading rate } \\
(\mathrm{mm} / \mathrm{min})\end{array}$ & $\begin{array}{l}\text { Maximum error } \\
(\mathrm{mm})\end{array}$ & $\begin{array}{l}\text { Average error } \\
(\mathrm{mm})\end{array}$ \\
\hline $\mathrm{U}_{\mathrm{S} 1}$ & 3 & 2.10 & 1.03 \\
$\mathrm{~W}_{\mathrm{S} 1}$ & 3 & 1.80 & 0.87 \\
$\mathrm{U}_{\mathrm{S} 2}$ & 1 & 2.40 & 1.01 \\
\hline
\end{tabular}

Table 4 The specifications of the cyclic loading tests

\begin{tabular}{llllll}
\hline Specimens & $\begin{array}{l}\text { Load fre- } \\
\text { quency } \\
(\mathrm{Hz})\end{array}$ & $\frac{\delta_{\max }^{2}}{\left[\delta_{\mathrm{cr}}\right]_{\mathrm{av}}^{2}}=\frac{\mathrm{G}_{\mathrm{Imax}}}{\mathrm{G}_{\mathrm{Ic}}}$ & $\delta_{\min }(\mathrm{mm})$ & $\delta_{\max }(\mathrm{mm})$ & $R=\frac{\delta_{\min }}{\delta_{\max }}$ \\
\hline $\mathrm{U}_{\mathrm{F} 1}$ & 3 & 0.8 & 1.2 & 3 & 0.4 \\
$\mathrm{~W}_{\mathrm{F} 1}$ & 3 & 0.8 & 2.4 & 6 & 0.4 \\
$\mathrm{U}_{\mathrm{F} 2}$ & 3 & 0.5 & 0.9 & 2.3 & 0.4 \\
$\mathrm{~W}_{\mathrm{F} 2}$ & 3 & 0.5 & 2 & 5 & 0.4 \\
\hline
\end{tabular}

$\delta_{\min }:$ minimum displacement for cyclic loading, $\delta_{\max }$ : maximum displacement for cyclic loading, $\delta_{\mathrm{cr}}$ : displacement corresponding to the crack initiation for the quasi-static loading, $\mathrm{G}_{\text {Imax }}$ : fracture energy release rate corresponded to $\delta_{\max }$ for the cyclic loading, $\mathrm{G}_{\mathrm{Ic}}$ : interlaminar fracture toughness calculated from the quasi-static mode I loading
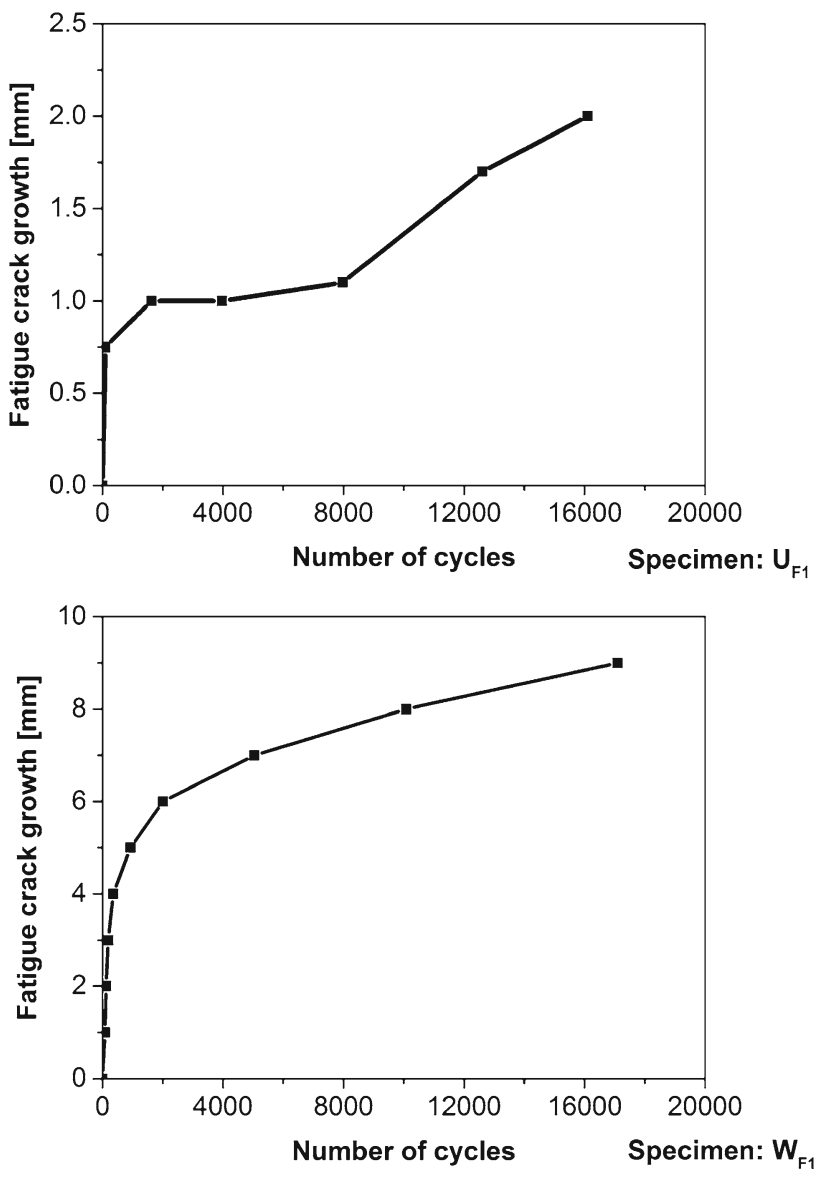

Fig. 14 The fatigue crack growth for the $U_{F 1}$ and $W_{F 1}$ specimens 

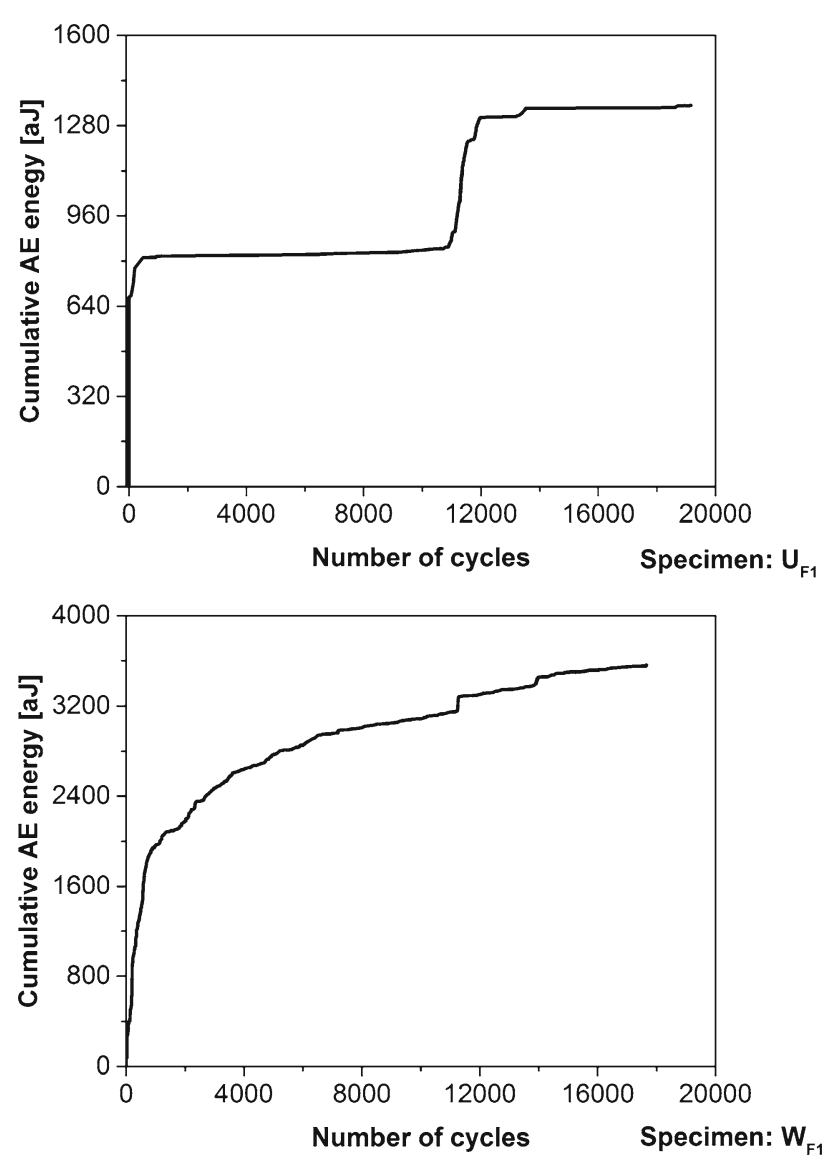

Fig. 15 Cumulative AE energy curve for the $U_{F 1}$ and $W_{F 1}$ specimens

Strain energy release rate in mode $\mathrm{I}\left(\mathrm{G}_{\mathrm{I}}\right)$ for a DCB specimen is calculated as follows [47]:

$G_{I}=-\frac{1}{B}\left(\frac{d U}{d a}\right)_{\Delta}=\frac{12 P^{2} a^{2}}{E B^{2} h^{3}}$

where $\mathrm{B}, \mathrm{P}, \mathrm{a}, \mathrm{E}, \mathrm{U}$, and $\mathrm{h}$ are the specimen width, applied load, initial crack length, young modulus, released strain energy, and a half thickness of the specimen, respectively. Thus, the elastic strain energy $(\Delta U)$ released due to growth of delamination length $(\Delta a)$ is calculated as follows:

$$
\begin{aligned}
d U & =-\frac{12 P^{2} a^{2}}{E B h^{3}} d a \\
\int_{0}^{\Delta U} d U & =-\int_{a}^{a+\Delta a} \frac{12 P^{2} a^{2}}{E B h^{3}} d a \\
\Delta U & =-\frac{4 P^{2}}{E B h^{3}}\left[(a+\Delta a)^{3}-a^{3}\right] \\
& =\alpha P^{2}\left[(a+\Delta a)^{3}-a^{3}\right]
\end{aligned}
$$

where $\alpha=-\frac{4}{E B h^{3}}$.
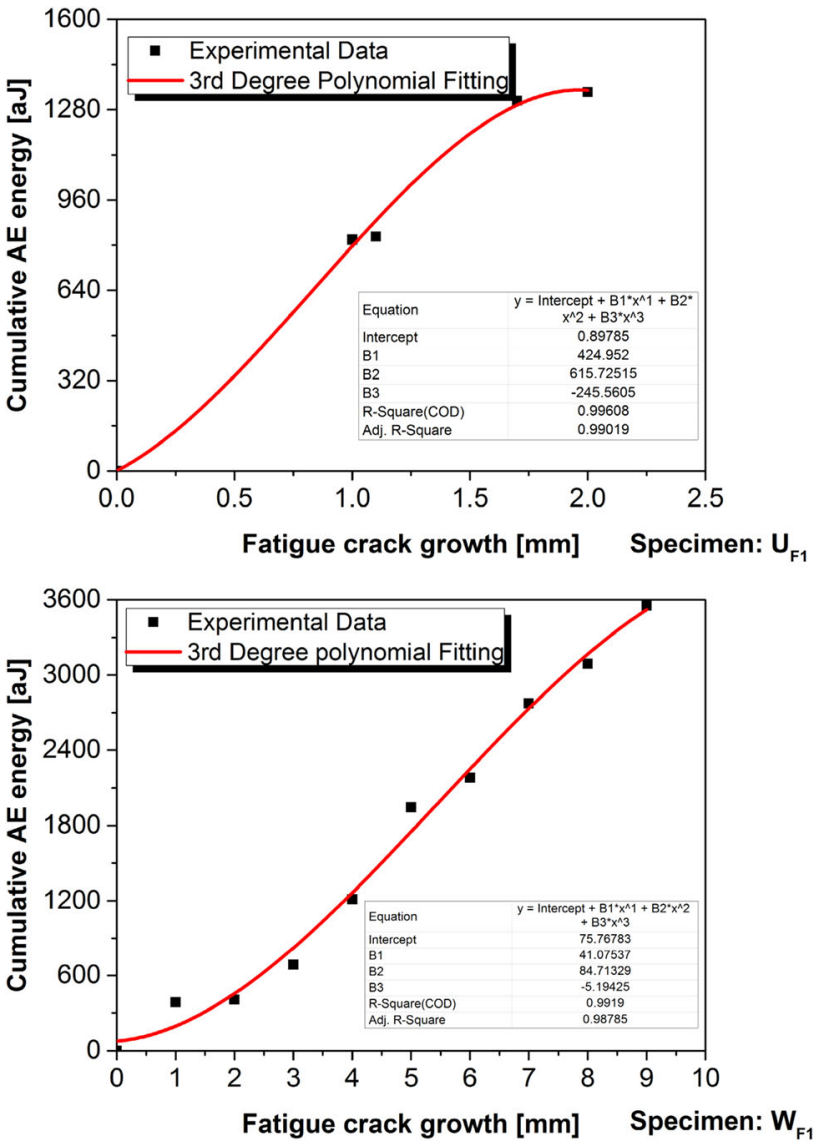

Fig. 16 Correlation between fatigue crack growth and cumulative $\mathrm{AE}$ energy for the $\mathrm{U}_{\mathrm{F} 1}$ and $\mathrm{W}_{\mathrm{F} 1}$ specimens

According to the linear relation of Fig. 10, combining Eqs. (2) and (6) leads to

$$
\begin{aligned}
\Delta E_{A E} & =\eta\left(\alpha P^{2}\left[(a+\Delta a)^{3}-a^{3}\right]\right)+\gamma \\
& =\beta P^{2}\left[(a+\Delta a)^{3}-a^{3}\right]+\gamma
\end{aligned}
$$

where $\beta=\eta \alpha . \eta$ and $\gamma$ are the coefficients of the linear equation of Fig. 10. Using $x^{3}-y^{3}=(x-y)\left(x^{2}+x y+y^{2}\right)$ substitution, Eq. (7) is modified as follows:

$$
\begin{aligned}
\Delta E_{A E} & =\beta P^{2}\left[(a+\Delta a)^{3}-a^{3}\right]+\gamma \\
& =\beta P^{2}\left[\Delta a^{3}+3 a \Delta a^{2}+3 a^{2} \Delta a\right]+\gamma
\end{aligned}
$$

Finally, Eq. (8) can be written as a general form as follows:

$E_{A E}=A_{1} \Delta a^{3}+A_{2} \Delta a^{2}+A_{3} \Delta a+A_{4}$

where $\mathrm{A}_{1}$ to $\mathrm{A}_{4}$ are the constants of the $3 \mathrm{rd}$ degree polynomial equation. 

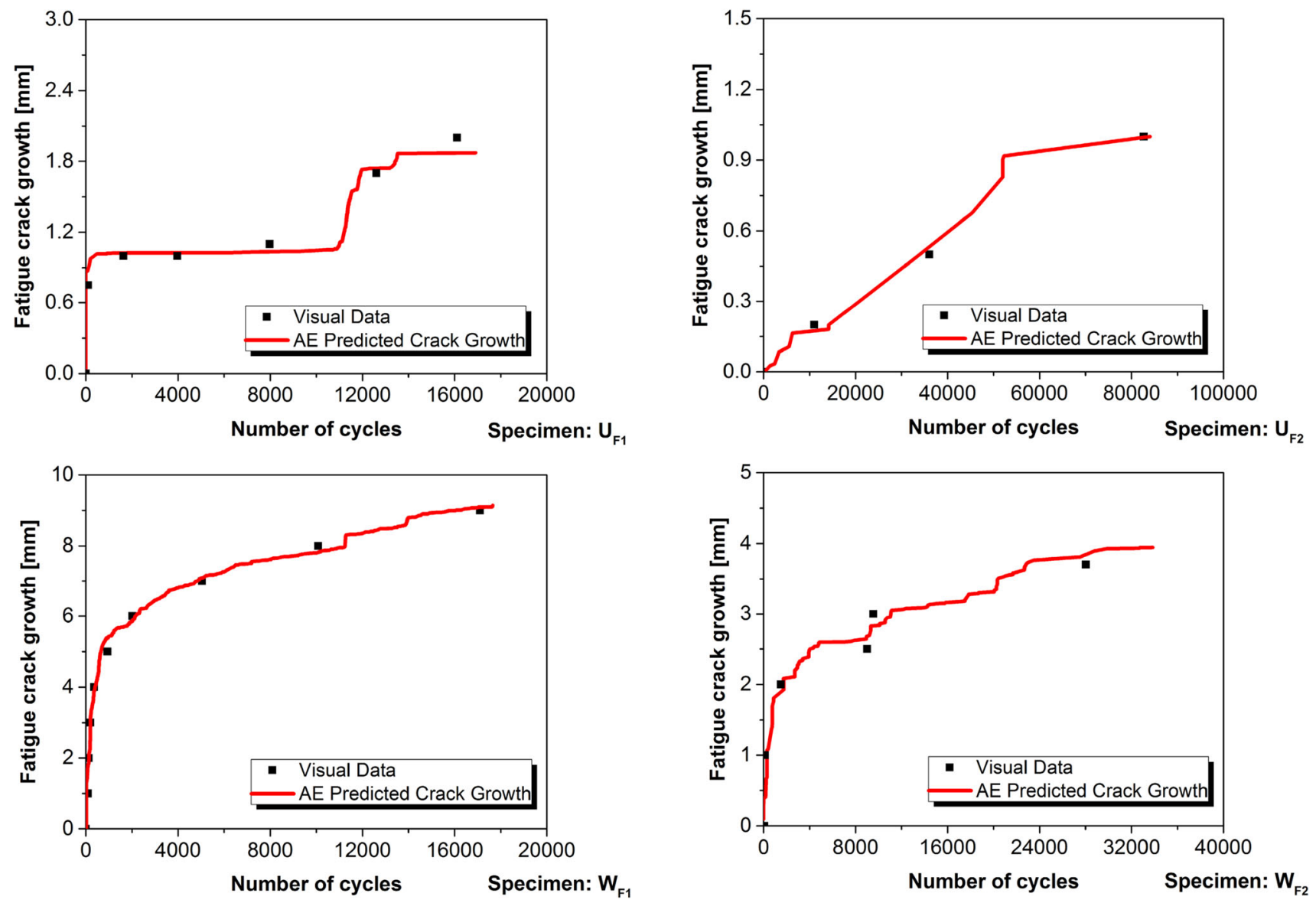

Fig. 17 Predicted and visually detected delamination fatigue crack growth for the $\mathrm{U}_{\mathrm{F} 1}$ and $\mathrm{W}_{\mathrm{F} 1}$ specimens

Figure 11 shows the correlation between the cumulative crack growth and the cumulative AE energy of delamination for the $\mathrm{U}_{\mathrm{S} 1}$ and $\mathrm{W}_{\mathrm{S} 1}$ specimens. A 3rd degree polynomial has been fitted to the data. Due to the very high values of the R-square and the adjusted R-square for the fittings, it is concluded that the 3rd degree polynomial of Eq. (9) truly expresses the correlation between the $E_{A E}$ and $\Delta a$.

The real root of Eq. (9) at a specific cumulative $\mathrm{AE}$ energy determines the crack growth value. Figure 12 shows the delamination crack growth estimated by cumulative $\mathrm{AE}$ energy versus visually recorded experimental data. As it is obvious, there is an excellent agreement between the results. In order to qualify the performance of the proposed method in different loading condition, another unidirectional specimen were tested with $1 \mathrm{~mm} / \mathrm{min}$ loading rate. Figure 13 shows the estimated delamination propagation curve versus the visually recorded curve for this specimen. As can be seen, by changing the loading condition, the AE method still can predict the delamination propagation precisely.

Table 3 represents the average and maximum differences between the predicted delamination crack growth by the $\mathrm{AE}$ method and the visually detected crack growth. The results

Fig. 18 Predicted and visually detected delamination fatigue crack growth for the $\mathrm{U}_{\mathrm{F} 2}$ and $\mathrm{W}_{\mathrm{F} 2}$ specimens

show that the proposed AE method has a good performance to predict quasi-static delamination crack growth.

\subsection{Fatigue Loading}

In order to evaluate the performance of the proposed AEbased method in a complicated loading condition, the fatigue loading tests were carried out. Some samples identical with the quasi-static specimens were subjected to the fatigue loading. The specifications of the fatigue loading tests are represented in Table 4.

Fatigue crack growth curves for the $\mathrm{U}_{\mathrm{F} 1}$ and $\mathrm{W}_{\mathrm{F} 1}$ specimens are illustrated in Fig. 14. As can be seen, the fatigue crack growth in the $\mathrm{W}_{\mathrm{F} 1}$ specimen is more stable than the $\mathrm{U}_{\mathrm{F} 1}$ specimen. Similar to the quasi-static loading, instability of the fatigue crack growth in the $\mathrm{U}_{\mathrm{F} 1}$ specimen refers to the fiber bridging phenomenon (see Fig. 4a).

\subsection{Prediction of Fatigue Crack Growth Using AE}

Cumulative $\mathrm{AE}$ energy of the $\mathrm{AE}$ signals originated from the delamination damage for the $\mathrm{U}_{\mathrm{F} 1}$ and $\mathrm{W}_{\mathrm{F} 1}$ specimens are 
Table 5 The maximum and average error of the $\mathrm{AE}$ fatigue crack growth prediction

\begin{tabular}{llll}
\hline Specimens & $\frac{G_{I \max }}{G_{I c}}$ & Maximum error $(\mathrm{mm})$ & Average error $(\mathrm{mm})$ \\
\hline $\mathrm{U}_{\mathrm{F} 1}$ & 0.8 & 0.12 & 0.06 \\
$\mathrm{~W}_{\mathrm{F} 1}$ & 0.8 & 0.30 & 0.14 \\
$\mathrm{U}_{\mathrm{F} 2}$ & 0.5 & 0.04 & 0.02 \\
$\mathrm{~W}_{\mathrm{F} 2}$ & 0.5 & 0.17 & 0.12 \\
\hline
\end{tabular}

illustrated in Fig. 15. Figure 16 shows the correlation between cumulative fatigue crack growth and cumulative AE energy of delamination for these specimens. Similar to the correlation between delamination growth and cumulative AE energy in quasi-static loading, there is a 3rd degree polynomial correlation between the cumulative fatigue crack growth and the cumulative AE energy. Due to the very high values of $\mathrm{R}$-square and the adjusted R-square for the fittings, it is concluded that the 3 rd degree polynomial fitting truly expresses the correlation between the cumulative fatigue crack growth and the cumulative AE energy.

Figure 17 illustrates the predicted fatigue crack growth and visually recorded crack growth for the $\mathrm{U}_{\mathrm{F} 1}$ and $\mathrm{W}_{\mathrm{F} 1}$ specimens. The results show that this method could precisely predict the fatigue crack growth.

In order to qualify the performance of the proposed method for different fatigue loading conditions, the $\mathrm{U}_{\mathrm{F} 2}$ and $\mathrm{W}_{\mathrm{F} 2}$ specimens were tested under lower stress levels $\left(\frac{\delta_{\max }^{2}}{\left[\delta_{c r}\right]_{a v}^{2}}=\frac{G_{\operatorname{Imax}}}{G_{I c}}=0.5\right)$. The predicted fatigue crack growth curve for these specimens are illustrated in Fig. 18.

Table 5 represents the average and maximum differences between the predicted fatigue crack growth by the AE method and the visually detected fatigue crack growth. The results show that the proposed AE method has an excellent performance to predict the delamination fatigue crack growth.

\section{Conclusion}

The aim of this study was to investigate the delamination propagation in glass/epoxy composites under mode I quasi-static and fatigue loading conditions. The results are represented in two sections. In the first section, correlations among the AE energy with the released strain energy and the crack growth were established based on the theoretical fundamentals. It was shown that there is a 3rd degree polynomial correlation between the cumulative AE energy of delamination and the cumulative crack growth and accordingly the quasi-static delamination crack growth was predicted using the AE method. In the second section, the delamination crack growth under the fatigue loading is predicted using the proposed AE method. The proposed AE method has some advantages such as predicting delamination growth using only one $\mathrm{AE}$ sensor without a need to determine $\mathrm{AE}$ wave propagation velocity in the specimens. This method is a robust technique for detecting and measuring the crack length, especially when the crack is hidden and could not be seen visually.

Open Access This article is distributed under the terms of the Creative Commons Attribution 4.0 International License (http://creativecommons. org/licenses/by/4.0/), which permits unrestricted use, distribution, and reproduction in any medium, provided you give appropriate credit to the original author(s) and the source, provide a link to the Creative Commons license, and indicate if changes were made.

\section{References}

1. Batra, R.C., Gopinath, G., Zheng, J.Q.: Damage and failure in low energy impact of fiber-reinforced polymeric composite laminates. Compos. Struct. 94, 540-7 (2012)

2. Minak, G., Morelli, P., Zucchelli, A.: Fatigue residual strength of circular laminate graphite- epoxy composite plates damaged by transverse load. Compos. Sci. Technol. 69, 1358-63 (2009)

3. Ramadas, C., Balasubramaniam, K., Joshi, M., Krishnamurthy, C.V.: Characterisation of rectangular type delaminations in composite laminates through B- and D-scan images generated using Lamb waves. NDT\&E Int. 44(3), 281-9 (2011)

4. Rolfes, R., Ernst, G., Vogler, M., Hühne, C.: Material and failure models for textile composites. In: Camanho, P.P., Dávila, C.G., Pinho, S.T., Remmers, J.J.C. (eds.) Mechanical Response of Composites, pp. 27-56. Springer, New York (2008)

5. Mechraoui, S.E., Laksimi, A., Benmedakhene, S.: Reliability of damage mechanism localization by acoustic emission on glass/epoxy composite material plate. Compos. Struct. 94, 148394 (2012)

6. Ativitavas, N., Fowler, T.J., Pothisiri, T.: Identification of fiber breakage in fiber reinforced plastic by low-amplitude filtering of acoustic emission data. J. Nondestr. Eval. 23(1), 21-36 (2004)

7. Arumugam, V., Suresh Kumar, C., Santulli, C., Sarasini, F., Stanley, A.J.: A global method for the identification of failure modes in fiberglass using acoustic emission. J. Test. Eval. 39(5), 1-13 (2011)

8. Sasikumar, T., Rajendraboopathy, S., Usha, K.M., Vasudev, E.S.: Artificial neural network prediction of ultimate strength of unidirectional T-300/914 tensile specimens using acoustic emission response. J. Nondestr. Eval. 27(4), 127-133 (2008)

9. Sridharan, S.: Delamination Behaviour of Composites. CRC Press, New York (2008)

10. Liu, P., Groves, R.M., Benedictus, R.: 3D monitoring of delamination growth in a wind turbine blade composite using optical coherence tomography. NDT\&E Int. 64, 52-8 (2014)

11. Allegri, G., Wisnom, M.R., Hallett, S.R.: A new semi-empirical law for variable stress-ratio and mixed-mode fatigue delamination growth. Compos. Part A. 48, 192-200 (2013) 
12. Chen, J.F., Morozov, E.V., Shankar, K.: Simulating progressive failure of composite laminates including in-ply and delamination damage effects. Compos. Part A. 61, 185-200 (2014)

13. Canturri, C., Greenhalgh, E.S., Pinho, S.T., Ankersen, J.: Delamination growth directionality and the subsequent migration processes-the key to damage tolerant design. Compos. Part A. 54, 79-87 (2013)

14. Hosseini Toudeshky, H., Hosseini, S., Mohammadi, B.: Delamination buckling growth in laminated composites using layerwiseinterface element. Compos. Struct. 92, 1846-56 (2010)

15. Benzeggagh, M.L., Kenane, M.: Measurement of mixed-mode delamination fracture toughness of unidirectional glass/epoxy composites with mixed-mode bending apparatus. Compos. Sci. Technol. 56, 439-49 (1996)

16. Fotouhi, M., Ahmadi Najafabadi, M.: Investigation of the mixedmode delamination in polymer-matrix composites using acoustic emission technique. J. Reinf. Plast. Compos. 33(19), 1767-82 (2014)

17. Camanho, P.P., Davila, C.G., De Moura, M.F.: Numerical simulation of mixed-mode progressive delamination in composite materials. J. Compos. Mater. 37(16), 1415-38 (2003)

18. Aghazadeh Mohandesi, J., Majidi, B.: Fatigue damage accumulation in carbon/epoxy laminated composites. Mater. Des. 30, 1950-6 (2009)

19. Chen, D., Gilbert, C.J., Ritchie, O.: In situ measurement of fatigue crack growth rates in a silicon carbide ceramic at elevated temperatures using a DC potential system. J. Test. Eval. 28(4), 236-41 (2000)

20. Miller, R.K.: Nondestructive Testing Handbook: Acoustic Emission Testing, 5th edn. American Society for Nondestructive Testing, Columbus (1987)

21. Kostopoulos, V., Loutas, T., Dassios, K.: Fracture behavior and damage mechanisms identification of $\mathrm{SiC} /$ glass ceramic composites using AE monitoring. Compos. Sci. Technol. 67, 1740-6 (2007)

22. Zhuang, X., Yan, X.: Investigation of damage mechanisms in selfreinforced polyethylene composites by acoustic emission. Compos. Sci. Technol. 66(3-4), 444-9 (2006)

23. McCrory, J.P., Al-Jumaili, S.K., Crivelli, D., Pearson, M.R., Eaton, M.J., Featherston, C.A., Guagliano, M., Holford, K.M., Pullin, R.: Damage classification in carbon fibre composites using acoustic emission: a comparison of three techniques. Compos. Part B. 68, 424-30 (2015)

24. Fotouhi, M., Heidary, H., Ahmadi, M., Pashmforoush, F.: Characterization of composite materials damage under quasi-static three point bending test using wavelet and fuzzy c-means clustering. J. Compos. Mater. 46(15), 1795-808 (2012)

25. Mizutani, Y., Nagashima, K., Takemoto, M., Ono, K.: Fracture mechanism characterization of cross-ply carbon-fiber composites using acoustic emission analysis. NDT\&E Int. 33(2), 101-10 (2000)

26. Pashmforoush, F., Khamedi, R., Fotouhi, M., Hajikhani, M., Ahmadi, M.: Damage classification of sandwich composites using acoustic emission technique and k-means genetic algorithm. J. Nondestr. Eval. 33(4), 481-492 (2014)

27. Suresh Kumar, C., Arumugam, V., Sajith, S., Dhakal, H.N., John, R.: Acoustic emission characterisation of failure modes in hemp/epoxy and glass/epoxy composite laminates. J. Nondestruct. Eval. 34, 31 (2015)

28. Refahi Oskouei, A., Ahmadi, M.: Acoustic emission characteristics of mode I delamination in glass/polyester composites. J. Compos. Mater. 44(7), 793-807 (2010)
29. Martínez-Jequier, J., Gallego, A., Suárez, E., Juanes, F.J., Valea, Á.: Real-time damage mechanisms assessment in CFRP samples via acoustic emission Lamb wave modal analysis. Compos. Part B. 68, 317-26 (2015)

30. Fotouhi, M., Saeedifar, M., Sadeghi, S., Ahmadi Najafabadi, M., Minak, G.: Investigation of the damage mechanisms for mode I delamination growth in foam core sandwich composites using acoustic emission. Struct. Health Monit. 14(3), 265-80 (2015)

31. Taghizadeh, J., Ahmadi, M.: Identification of damage modes in polypropylene/epoxy composites by using principal component analysis on AE signals extracted from Mode I delamination. Nondestruct. Test. Eval. 27(2), 151-70 (2012)

32. Silversides, I., Maslouhi, A., Laplante, G.: Interlaminar fracture characterization in composite materials by using acoustic emission. 5th International Symposium on NDT in Aerospace, Singapore, (2013)

33. Fotouhi, M., Ahmadi Najafabadi, M.: Acoustic emission-based study to characterize the initiation of delamination in composite materials. J. Thermoplast. Compos. Mater. 29(4), 519-37 (2016)

34. Arumugam, V., Sajith, S., Stanley, A.J.: Acoustic emission characterization of failure modes in GFRP laminates under mode I delamination. J. Nondestr. Eval. 30(3), 213-9 (2011)

35. Saeedifar, M., Fotouhi, M., Ahmadi Najafabadi, M., Hosseini Toudeshky, H.: Interlaminar fracture toughness evaluation in glass/epoxy composites using acoustic emission and finite element methods. J. Mater. Eng. Perform. 24(1), 373-84 (2015)

36. Silversides, I., Maslouhi, A., Laplante, G.: Acoustic emission monitoring of interlaminar delamination onset in carbon fibre composites. Struct. Health Monit. 12(2), 126-40 (2013)

37. Romhany, G., Szebényi, G.: Interlaminar fatigue crack growth behavior of MWCNT/carbon fiber reinforced hybrid composites monitored via newly developed acoustic emission method. Express Polym. Lett. 6(7), 572-80 (2012)

38. ASTM D5528-01. Standard Test Method for Mode I Interlaminar Fracture Toughness of Unidirectional Fiber-Reinforced Polymer Matrix Composites. ASTM International, West Conshohocken (2007)

39. ASTM: D6115-97: Standard Test Method for Mode I Fatigue Delamination Growth Onset of Unidirectional Fiber-Reinforced Polymer Matrix Composites. ASTM International, West Conshohocken (2011)

40. Mandorini, V., Ghelardoni, E., Tribuno, C.: Acoustic energy during pop-in crack propagation. Eng. Fract. Mech. 15(3-4), 255-73 (1981)

41. Hiley, M.J.: Delamination between multi-directional ply interfaces in carbon-epoxy composites under static and fatigue loading. In: Williams, J.G., Pavan, A. (eds.) Fracture of Polymers, Composites, and Adhesives, pp. 61-72. Elsevier, Amsterdam (2000)

42. Andersons, J., König, M.: Dependence of fracture toughness of composite laminates on interface ply orientations and delamination growth direction. Compos. Sci. Technol. 64(13-14), 2139-52 (2004)

43. Bandaru, A.K., Ahmad, S.: Modeling of progressive damage for composites under ballistic impact. Compos. Part B. 93, 75-87 (2016)

44. Aymerich, F., Dore, F., Priolo, P.: Simulation of multiple delaminations in impacted cross-ply laminates using a finite element model based on cohesive interface elements. Compos. Sci. Tech. 69, 1699-709 (2009)

45. Zhang, J., Zhang, X.: Simulating low-velocity impact induced delamination in composites by a quasi-static load model with surface-based cohesive contact. Compos. Struct. 125, 51-7 (2015) 
46. Andrew, J.J., Arumugam, V., Saravanakumar, K., Dhakal, H.N., Santulli, C.: Compression after impact strength of repaired GFRP composite laminates under repeated impact loading. Compos. Struct. 133, 911-20 (2015)

47. Anderson, T.L.: Fracture Mechanics; Fundamentals and Applications, 4th edn. Taylor \& Francis, Boca Raton (2005)
48. Gerberich, W.W., Hartbower, C.E.: Some observations on stress wave emission as a measure of crack growth. Int. J. Fract. Mech. 3(3), 185-92 (1967) 